\title{
A Framework to Guide Educational Technology Studies in the Evolving Classroom Research Environment
}

\author{
Tomohiro Nagashima, Gautam Yadav, and Vincent Aleven. \\ Human-Computer Interaction Institute, Carnegie Mellon University, \\ Pittsburgh, USA \\ \{tnagashi, gyadav, va0e\} dandrew.cmu.edu
}

\begin{abstract}
Despite the drastic change to school environments due to the COVID19 pandemic, it is still important that educational technology researchers conduct school-based research to understand the impact of technology in an authentic learning context, even remotely. However, the transition to remote research has made it challenging for researchers to collect classroom data, observe teacherstudent-technology interactions, and facilitate study sessions. To explore how researchers can effectively plan and conduct technology-based educational studies in the new, evolving classroom research environment, we interviewed seven US teachers, investigating their perceptions of participating in remote classroom studies. Based on the findings and the authors' experience of running classroom studies, we propose a framework that educational technology researchers can refer to when planning and conducting research in the evolving classroom research environment. Specifically, the framework informs researchers of several types of questions they can explore with teachers, students, and researchers themselves to be better prepared to address potential confusion, unexpected issues, and practical benefits in remote classroom research. Our work contributes by providing a practical guide for running technology-based research remotely, which may remain as a means of classroom research in the future. Some of the findings and the framework would also be applied to in-person classroom research setting.
\end{abstract}

Keywords: Classroom Research, COVID-19, Remote Teaching and Learning.

\section{Introduction}

\subsection{Classroom Studies in Educational Technology Research}

For decades, researchers of educational technologies have studied the effectiveness and use of educational technologies in the context of school classrooms. For example, researchers conduct "in-vivo" experiments to examine the effectiveness of instructional approaches embedded in educational software in a classroom context [1]. An in-vivo experiment in education research is a study conducted in an actual classroom setting, as opposed to in a research lab setting, in an attempt to maximize both internal and external validity of the study [1]. Examples of an in-vivo study include efficacy studies using learning software and classroom evaluations of AI-based tutoring software where 
students are assigned to use learning software and researchers collect data generated from the software and other instruments such as online surveys and tests [1, 2]. Classroom studies are also employed in other types of educational research conducted with practitioners, such as in Design-Based Research and Researcher-Practitioner Partnerships $[3,4]$. Classroom studies with educational technologies can take a variety of formats (e.g., observational studies, randomized control trials). Regardless of the study format, classroom studies consider regular classroom features, such as teacher-student interactions and resources available in the classroom, as part of the study context.

The current paper considers how classroom research with educational technology can be conducted effectively in the evolving classroom research environment in which different levels of remote involvement by researchers is possible, brought about mainly by the COVID-19 pandemic [5, 6]. We believe that remote involvement in classroom research may continue to exist in some form in the near future due to its advantages (e.g., remote classroom research allows researchers to conduct research with schools located in areas where study participation opportunities are not available) [7]. From among the various types of classroom studies, we focus on in-vivo educational studies.

\subsection{Conducting Classroom Research Remotely}

In the year 2020, due to the spread of the coronavirus disease (COVID-19), a vast number of schools across the globe were forced to make a transition to remote instruction [8]. In response to the shift, researchers were required to pivot to collecting data remotely using technologies such as video conferencing systems [7, 9]. Conducting classroom studies remotely, however, can be challenging and can affect study design and outcomes significantly. First, the mode of teaching at the school and that of researcher participation affect ways in which communications, data collection, and study facilitation happen. Figure 1 shows six different modes in which classroom research can be conducted, the traditional in-person classroom research mode and five remote classroom research modes. We developed this schematic based on our experience of running in-person and remote classroom studies at six schools with ten teachers before and during the pandemic [2]. Compared to the traditional classroom research mode (Figure 1, A), where all stakeholders are physically located in the same classroom, remote classroom research can vary depending on whether the school/class adopts in-person or remote teaching, synchronous or asynchronous teaching, and whether and how the researcher helps run the study with the teacher synchronously or asynchronously, including any technical and logistical support the research team may provide. For instance, direct researcher-student interactions are more likely to happen when the researcher, teacher(s), and students are all synchronously connected in a video-conferencing system than in situations where students participate in classroom research asynchronously (i.e., completing assigned study tasks whenever students have time).

Secondly, data collection can be affected by the affordances and constraints of communication technologies used for remotely connecting researchers and participants (e.g., video conferencing systems) [5]. For example, in a fully-remote synchronous session (Figure 1, D), it becomes difficult to observe teacher-student interactions if the study uses a platform that allows participants to privately message each other. Also, it 
is challenging to observe students' gestures and facial expressions since students might not have a web camera, or even when they have one, students might not turn it on [10].

Finally, it is important to consider teachers' and students' experiences (e.g., benefits and concerns) in participating in research conducted remotely. Classroom studies are a means for researchers to visit an authentic learning environment and understand the impact of the technology in situ [1]. Understanding what practical benefits educational technology research (remote or in-person) can offer to teachers and students, and what concerns may be mitigated, will help design classroom research as a mutual learning opportunity between researchers and teachers and students rather than as a mere means of data collection. It is particularly important to understand such practitioners' perspectives on participating in remote research, caused due to the COVID-19 pandemic. As the pandemic has already created and will continue creating many struggles for students (e.g., lack of emotional support and device access, increased family responsibilities) [11] and for teachers (e.g., increased workload, burnout) [12], educational technology research should not cause any additional burdens and stress to teachers and students. Therefore, it is critical that researchers understand practical benefits and challenges/concerns that teachers and students might have and appropriately address them when conducting research in the evolving classroom research environment.

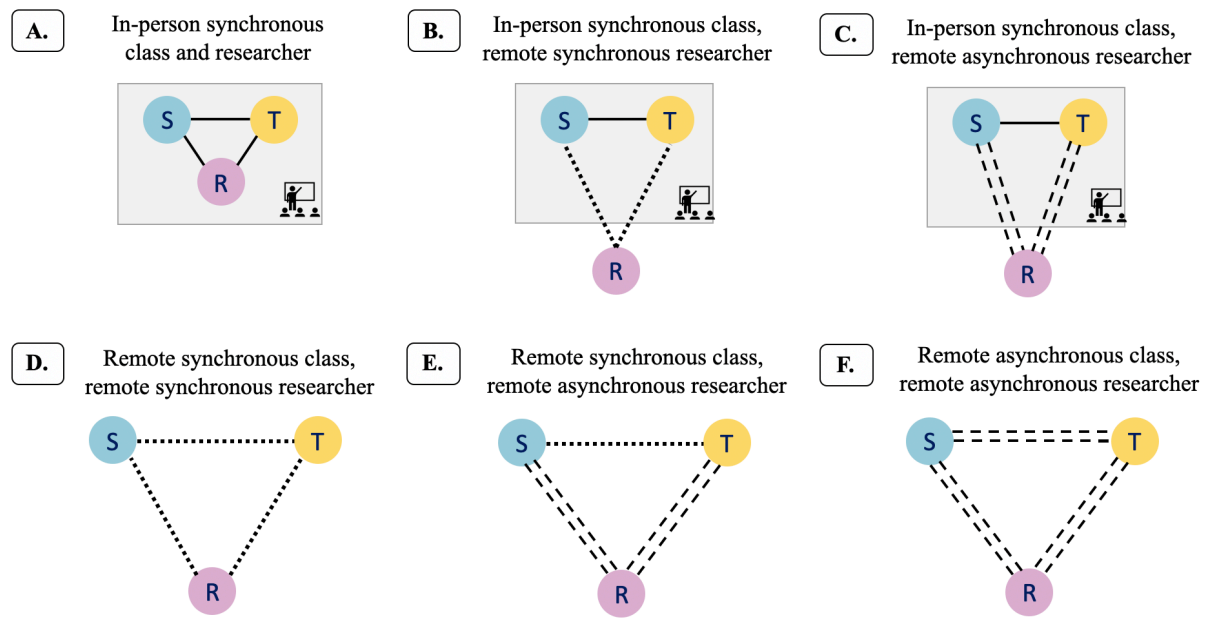

Fig. 1. Modes of remote and in-person classroom research. "S", "T", and "R" represent student, teacher, and researcher, respectively. Solid lines indicate in-person synchronous interaction, dotted lines show remote synchronous interaction, and double dashed lines indicate remote asynchronous interaction. Gray squares show that stakeholders in the square are in the physical classroom. Model A shows the in-person classroom research model. The authors experienced all six modes in their classroom research. Hybrid (mix of in-person and remote) teaching mode can be represented by combining Models B and D (synchronous hybrid class, remote synchronous researcher) or $\mathrm{C}$ and $\mathrm{E}$ (synchronous hybrid class, remote asynchronous researcher).

Given these considerations for classroom research conducted remotely, it is essential that researchers of educational technology understand potential factors that might affect data collection, communications, and teacher and student experience when conducting 
technology-based educational research. Understanding such pragmatic factors will help create a sustainable model for running research in the evolving classroom research environment. Prior related work provides some guidance for how to conduct remote data collection, such as when conducting co-design activities with children [5] and remote user studies in the field of Human-Computer Interaction $[6,13]$. However, to the best of our knowledge, there is no prior work that guides remote research studies in (physical or virtual) school environments. Educational studies in classrooms are uniquely different from typical user studies or other types of studies that are conducted in a lab, or in a relatively confined setting. In a teaching and learning environment, interactions are complex since multiple stakeholders (e.g., teachers, students, and peers) interact with each other dynamically in unpredictable ways [14]. To inform researchers what aspects to be mindful of in running classroom studies, particularly in the remote setting, we conducted interviews with US teachers exploring their perceptions of participating in classroom studies. Based on the findings and our own experience of running in-person and remote studies, we propose a framework that researchers can use to help develop their remote study plans.

\section{Method}

\subsection{Participants}

To conduct interviews, we recruited middle-school $(n=6)$ and high-school $(n=1)$ mathematics teachers in the United States. We specifically targeted mathematics teachers because mathematics is the task domain of our on-going research. We targeted teachers who, in earlier interactions, had expressed an interest in participating in classroom studies with us during their remote instruction (March - June 2020). Three of the participating teachers had remotely participated in a study with us during May - June 2020, prior to the interview. In the study, their students used an Intelligent Tutoring System for algebra [2]. One other teacher had participated in classroom research with their students before the COVID-19 pandemic. The remaining three teachers had not participated in classroom research before. The teachers were recruited either via teacher groups on a social networking site or from previous contacts. Their level of experience in using educational technology varied. Lastly, all teachers' schools were affected significantly by the pandemic; they were required to make a transition to either fully-remote synchronous instruction $(n=4)$ or fully-remote asynchronous instruction $(n=3)$.

Interviews were conducted individually and remotely using a video conferencing system. Each interview lasted approximately an hour. The interviews were semi-structured; the researchers asked both pre-planned questions and un-planned questions as the conversation evolved. The interviews explored teachers' perceptions regarding participating in classroom research in general (e.g., "What kinds of benefits do you think participating in classroom research will bring to you and your students?" and "how would you describe the study participation opportunity to your students?") and those specific to remote study participation (e.g., "What kinds of emerging factors during remote teaching you think might affect data collection and student learning?"). Three 
of the teachers participated in one or two additional sessions to continue the interview. In total, we conducted 11 one-hour interview sessions.

\subsection{Data Collection and Analysis}

All interviews were video-recorded and transcribed for analysis. Two learning sciences graduate students analyzed the data following an Affinity Diagramming approach, a commonly-used method for analyzing qualitative data through grouping and organizing quotes and codes into a hierarchy of themes [15]. The graduate students communicated frequently to resolve any disagreements. We obtained a total of 179 codes, clustered into 70 mid-level themes. We grouped the mid-level themes into seven major themes.

\section{$3 \quad$ Results}

Our analysis revealed seven major themes regarding teachers' perceptions on participating in remote classroom studies, categorized into benefits and concerns/challenges (Table 1). In what follows, we describe these themes in the two categories in turn.

Table 1. Benefits and concerns/challenges teachers perceive for participating in remote classroom studies.

\begin{tabular}{ll}
\hline \multicolumn{1}{c}{ Perceived Benefits } & \multicolumn{1}{c}{ Perceived Concerns/Challenges } \\
\hline $\begin{array}{l}\text { B1: Teachers appreciate the opportunity to } \\
\text { make a real-world connection by remotely } \\
\text { welcoming researchers to the classroom }\end{array}$ & $\begin{array}{l}\text { C1: Teachers find it hard to calibrate their } \\
\text { level of intervention/facilitation during studies }\end{array}$ \\
\hline $\begin{array}{ll}\text { B2: Teachers consider that remote study par- } \\
\text { ticipation can be a motivating activity for }\end{array}$ & $\begin{array}{l}\text { C2: Teachers prefer customizability and flexi- } \\
\text { bility regarding research participation and } \\
\text { content to-be-covered }\end{array}$ \\
\hline $\begin{array}{ll}\text { B3: Teachers will have an opportunity to un- } \\
\text { derstand their students from a different per- }\end{array}$ & $\begin{array}{l}\text { C3: Teachers are concerned with the lack of } \\
\text { synchronous, immediate support for students } \\
\text { spective }\end{array}$ \\
\hline & $\begin{array}{l}\text { C4: Teachers are concerned with students' } \\
\text { learning environments during remote teaching }\end{array}$ \\
\hline
\end{tabular}

\subsection{Perceived Benefits of Participating in Remote Classroom Research}

B1: Teachers Appreciate the Opportunity to Make a Real-World Connection by Remotely Welcoming Researchers to the Classroom. All teachers strongly emphasized the importance of connecting their students with researchers, consistent with findings in prior literature [16]. Teachers view welcoming researchers in the classroom as an opportunity for students to learn about real-world jobs (e.g., knowing what researchers do). For instance, one teacher, who participated in a study in June 2020 when the teacher remotely and asynchronously taught students, stated that their students had had very limited exposure to the outside world even before the transition to remote teaching: 
[We] are a very small community [...] so a lot of kids don't know what's out there [...]. They haven't been out in the real world. A lot of them haven't even traveled beyond our edge of our city. [...]. So I was looking for ways to connect what we're doing in math to either like a career field or something in their real life.

Importantly, the need for real-world connections in classrooms has become more critical during remote learning because students have fewer opportunities to interact with the world outside the classroom and their homes. As an overall trend, we found that teachers who teach in a suburban area, including the teacher whose quote is shown above, shared that remote classroom research gives a meaningful research participation experience to their students, who used to have limited access to such opportunities before the transition to remote instruction.

B2: Teachers Consider that Remote Study Participation can be a Motivating Activity for Students. Teachers mentioned that, as it became very challenging for students to keep up their motivation and engagement during remote teaching, participating in a study could be a huge motivator that would "bring students back to the classroom," which they hoped to do but found challenging. Indeed, several of the teachers we interviewed reported that their virtual class participation rate was only about $10-15 \%$. They also said that they expect that an opportunity to contribute to the science of teaching and learning will be motivating for their students. They told us that they would emphasize that helping researchers would make the world better and that their students' effort would be key to the success of the research.

B3: Teachers will Have an Opportunity to Understand their Students from a Different Perspective. Teachers noted that participating in a study would allow them to view their students from a different perspective. Specifically, teachers said that they would appreciate an opportunity to observe how students perform the assigned tasks in the educational technology used. Teachers stated that watching how their students approach the task would give them a new point of view regarding individual students that they would not otherwise gain from their daily instruction. In this sense, teachers are curious about researchers' scientific inquiries and keen to learn from research results.

Teachers also consider research participation an opportunity to try new types of instruction or digital technologies and find out what kinds of educational technology or tools their students find engaging. Although the benefit of being able to understand students from a different perspective could well apply to an in-person setting, all interviewed teachers had a hard time coping with students' low motivation and engagement and they were therefore looking for ways to maintain or enhance participation and engagement more often during remote teaching than before. 


\subsection{Perceived Concerns and Challenges regarding Participation in Remote Classroom Research}

\section{C1: Teachers Find it Hard to Calibrate their Level of Intervention/Facilitation} during Studies. As the data collection became virtual, interactions among teachers, students, and researchers during the study, including during the study sessions themselves, became dependent on the affordances and constrains of the technology used for having interactions. For example, the use of a synchronous video conferencing system might facilitate researcher-student interactions; by contrast, if email is the only technology used for communications, there is no opportunity for synchronous interaction. Therefore, depending on the type of technology used for running remote studies, a situation could conceivably happen where, for example, students and researchers directly communicate with each other without including their teacher. Conversely, researchers might be able to interact with students only through the help of teachers (e.g., researchers are not allowed to send emails to students directly). This tension regarding how much researchers' and teachers' involvement are ideal came up frequently during the interviews. Although teachers said they would want the researchers to lead the study, they stressed that it was important that they could be a "facilitator" of the study. They noted that it is important that researchers describe the study because that would motivate students but they consider their own involvement essential, especially during remote teaching. This desire comes from concerns regarding the lack of cues and strategies that they used to have during in-person teaching as well as limited communication channels between students and teachers during remote teaching [17].

Another reason that teachers gave for wanting to be actively facilitating research studies is that they have better knowledge than researchers about which students are struggling and how to help them (e.g., they know which students regularly ask for help). Therefore, they would like to be informed or involved when researchers communicate with students. One teacher shared how much researcher involvement would be ideal:

I do think it's important to have a teacher being the facilitator of that kind of the relationship then between [our] students and the actual study. The idea that the students have formed a relationship with me [...]. But on the other hand, it's not my project. So I think it's a good idea for [a researcher] to explain the research to them [...]. I do think it's good for [a researcher] to be involved [...] but also, I think they are more comfortable if they know that I'm explaining the procedure.

C2: Teachers Prefer Customizability and Flexibility regarding Research Participation and Content To-be-Covered. Teachers prefer having the ability to customize what content their students will work on during the study, or at least having a few options for the task assignment. They also prefer studies that are aligned with their teaching practices. Customization and flexibility in research design are perceived as a critical factor for teachers to decide whether or not to participate in the remote study. 
C3: Teachers are Concerned with the Lack of Synchronous, Immediate Support for Students in Remote Studies. All teachers expressed concern regarding what to do if a student would face technical trouble or struggle with the content in the technology used in the study during a remote study (e.g., students might have trouble when they log into the system). Supporting students remotely during such an event would be challenging, compared to doing so in the in-person regular classroom environment. In fact, teachers' concern that it would be challenging for their students to learn to use the technology was a major reason that some of them decided not to participate in our proposed study during remote teaching, despite having previously expressed interest in doing so.

C4: Teachers are Concerned with Students' Learning Environments During Remote Teaching. Teachers indicated that there are new, unique challenges that affect student learning during remote teaching. As reported in the literature $[11,12]$, teachers stated that their students were struggling due to lack of access to the internet, lack of parental and peer support, and lack of access to the physical books that they had used. As both students and teachers found it very challenging to connect with each other to keep the classroom instruction going [17], in spite of trying hard, teachers were hesitant to introduce anything new (technology or topic) to their students during remote teaching, lest it causes their students additional confusion and adds to their workload.

\section{Discussion}

\subsection{A Framework for Conducting Remote Classroom Research}

The interviews highlight benefits of participating in educational research in the evolving classroom research environment and concerns/challenges perceived by teachers. All the themes we found (except C3 and C4) could arguably be applied to in-person research setting, but we found that these themes have much greater importance in a remote setting (e.g., teachers' desire for students to get exposed to a real-world experience would still apply to in-person classroom research, but teachers stressed the importance of it in a remote setting). Despite the unpredictable future, we believe that conducting classroom studies virtually will remain important as schools may consider a virtual learning environment as one of the possible teaching modes or researchers may keep conducting research remotely due to a school's policy regarding visitors and/or due to advantages of remote research (e.g., researchers do not need to travel to the study site and their sample will not be constrained in specific locations).

Based on the interviews, we offer a framework that researchers can use to guide their research in the evolving classroom research environment (Table 2). The framework captures factors that researchers need to be aware of when preparing for and running classroom studies remotely. We think that providing such a framework, rather than concrete recommended strategies, would be more useful because of the unpredictable and uncontrollable nature of remote research [5]. The framework provides guiding questions that researchers can use to explore needs, preferences, and expectations among teachers, students, and researchers themselves. The questions help researchers 
better address dimensions that we consider are critical when planning and conducting remote classroom research. During our own remote classroom studies, we found these guiding questions helped understand the school's context, teachers' needs and preferences, and realize our (researchers') own expectations. We describe each of the dimensions below.

Table 2. A framework for addressing factors that might affect remote classroom research. Each question in a cell represents a guiding question that the researcher can ask the corresponding stakeholder (teacher, student, or researcher themselves). Code in parentheses (e.g., B1) represents the associated theme(s) that the dimension is drawn from.

\begin{tabular}{|c|c|c|c|}
\hline $\begin{array}{c}\text { Dimension } \\
\text { and Objective }\end{array}$ & Teacher & $\begin{array}{l}\text { Question for: } \\
\text { Student }\end{array}$ & Researcher \\
\hline $\begin{array}{l}\text { Study Facilitation } \\
(\mathbf{C 1}, \mathbf{C 3}) \\
\text { - To communicate } \\
\text { expectations and } \\
\text { preferences on } \\
\text { what to do when } \\
\text { unexpected events } \\
\text { occur }\end{array}$ & $\begin{array}{l}\text { - What are the } \\
\text { teacher's expecta- } \\
\text { tions and prefer- } \\
\text { ences regarding } \\
\text { who will lead } \\
\text { study sessions, } \\
\text { and how they will } \\
\text { do so? }\end{array}$ & $\begin{array}{l}\text { - How would } \\
\text { students feel } \\
\text { about com- } \\
\text { municating di- } \\
\text { rectly with re- } \\
\text { searchers? }\end{array}$ & $\begin{array}{l}\text { - How critical is it } \\
\text { that the researcher } \\
\text { takes the lead in fa- } \\
\text { cilitating study ses- } \\
\text { sions? } \\
\text { - How can research- } \\
\text { ers help teachers be } \\
\text { prepared for their } \\
\text { preferred role as a fa- } \\
\text { cilitator? }\end{array}$ \\
\hline $\begin{array}{l}\text { Resource Access } \\
\text { (B2, B3) } \\
\text { - To understand } \\
\text { and address the } \\
\text { needs and desires } \\
\text { of participants re- } \\
\text { garding resource } \\
\text { access }\end{array}$ & $\begin{array}{l}\text { - What data, re- } \\
\text { sources, and tools, } \\
\text { would the teacher } \\
\text { want to use for } \\
\text { their own teaching } \\
\text { or for understand- } \\
\text { ing their students } \\
\text { better? }\end{array}$ & $\begin{array}{l}\text { - What data, re- } \\
\text { sources, and } \\
\text { tools would stu- } \\
\text { dents find use- } \\
\text { ful if they were } \\
\text { given free ac- } \\
\text { cess? }\end{array}$ & $\begin{array}{l}\text { - How to make the } \\
\text { data, resources, and } \\
\text { tools open enough so } \\
\text { that participants can } \\
\text { use them outside the } \\
\text { research context (e.g., } \\
\text { platform choice, cus- } \\
\text { tomization)? }\end{array}$ \\
\hline \multirow{2}{*}{$\begin{array}{l}\text { - To understand } \\
\text { and address par- } \\
\text { ticipants' motiva- } \\
\text { tions for partici- } \\
\text { pating in the re- } \\
\text { search }\end{array}$} & $\begin{array}{l}\text { - What would the } \\
\text { teacher want to } \\
\text { learn about stu- } \\
\text { dents, the re- } \\
\text { search, and the } \\
\text { educational tech- } \\
\text { nology used? }\end{array}$ & $\begin{array}{l}\text { - What would } \\
\text { help motivate } \\
\text { students to par- } \\
\text { ticipate and en- } \\
\text { gage in the re- } \\
\text { search? }\end{array}$ & $\begin{array}{l}\text { - What would the re- } \\
\text { searcher want the } \\
\text { teacher and students } \\
\text { to gain from partici- } \\
\text { pating in the re- } \\
\text { search? }\end{array}$ \\
\hline & $\begin{array}{l}\text { - What would the } \\
\text { teacher want stu- } \\
\text { dents to gain from } \\
\text { participating in } \\
\text { the study? }\end{array}$ & $\begin{array}{l}\text { - What kinds of } \\
\text { real-world con- } \\
\text { nections would } \\
\text { students be in- } \\
\text { terested in mak- } \\
\text { ing or hearing } \\
\text { about? }\end{array}$ & $\begin{array}{l}\text { - What kinds of real- } \\
\text { world connections } \\
\text { could the researcher } \\
\text { provide to students? }\end{array}$ \\
\hline
\end{tabular}




\begin{tabular}{|c|c|c|c|}
\hline $\begin{array}{l}\text { Study Logistics and } \\
\text { Context Alignment } \\
(\mathbf{C 2}, \mathbf{C 3 )} \\
\text { - To make the } \\
\text { study participa- } \\
\text { tion easy and } \\
\text { straightforward } \\
\text { - To ensure that } \\
\text { the study is } \\
\text { aligned with the } \\
\text { classroom practice }\end{array}$ & $\begin{array}{l}\text { - What tool does } \\
\text { the teacher use } \\
\text { that could be inte- } \\
\text { grated into the re- } \\
\text { search (or that the } \\
\text { research could be } \\
\text { integrated into)? } \\
\text { - How closely is } \\
\text { the study topic } \\
\text { aligned with } \\
\text { classroom teach- } \\
\text { ing? }\end{array}$ & $\begin{array}{l}\text { - What tools are } \\
\text { students already } \\
\text { familiar with? } \\
\text { - Are there top- } \\
\text { ics that students } \\
\text { are interested in } \\
\text { (e.g., out-of- } \\
\text { school interests) } \\
\text { that could be in- } \\
\text { tegrated into the } \\
\text { research? }\end{array}$ & $\begin{array}{l}\text { - What are some pos- } \\
\text { sible ways that the } \\
\text { study activities can } \\
\text { be streamlined and } \\
\text { made as simple as } \\
\text { possible so that par- } \\
\text { ticipants can carry } \\
\text { out these activities } \\
\text { easily? }\end{array}$ \\
\hline $\begin{array}{l}\text { Equity in Partici- } \\
\text { pation (C4) } \\
\text { - To understand } \\
\text { individual differ- } \\
\text { ences in partici- } \\
\text { pants' learning } \\
\text { environments }\end{array}$ & $\begin{array}{l}\text { - What does the } \\
\text { teacher know } \\
\text { about their stu- } \\
\text { dents' learning } \\
\text { environments and } \\
\text { about how to ef- } \\
\text { fectively support } \\
\text { students during } \\
\text { remote learning? }\end{array}$ & $\begin{array}{l}\text { - What kinds of } \\
\text { learning envi- } \\
\text { ronments and } \\
\text { support (e.g., } \\
\text { from parents, } \\
\text { and siblings) do } \\
\text { students have } \\
\text { access to? }\end{array}$ & $\begin{array}{l}\text { - How can the re- } \\
\text { search address/con- } \\
\text { sider students' learn- } \\
\text { ing environments? } \\
\text { - What are alternative } \\
\text { ways for students to } \\
\text { participate in the re- } \\
\text { search if they do not } \\
\text { have adequate learn- } \\
\text { ing environments? }\end{array}$ \\
\hline
\end{tabular}

Study Facilitation. It is important that researchers clearly understand teachers' expectations and preferences regarding whether and how teachers want to take the lead in running study sessions. We found that teachers are concerned with how to help run the study and provide appropriate, immediate support for students. Although it is important to understand teachers' and students' needs and preferences in any classroom study, including those conducted in-person, it is especially important in remote research. Such understanding will help researchers develop a study plan that the teachers and students feel comfortable with and that can accommodate unique situations that might happen in remote setting. For instance, researchers need to ensure that teachers understand what to do when a sudden internet or electricity outage happens in a remote study because it can be challenging to make decisions dynamically in such a situation [5].

Resource Access. Teachers like to be informed about study results to better understand their students. As well, they are curious to learn about research-based instructional knowledge and possibly incorporate it into their practices. Understanding these needs of practitioners will help researchers share resources that are most useful for the practitioners. For example, teachers might not only want access to students' learning data that researchers typically provide but might also appreciate receiving other types of data, such as how frequently students access the system in an asynchronous setting, to get insights into their students' behaviors that the teachers would not otherwise know. 
Also, if teachers and students are interested in further customizing study resources, it is important that researchers provide access to their resources in a customizable way (e.g., use an editable file and an open license).

Motivation. To maximize practical benefits for teachers and students, we recommend that researchers understand teachers' and students' motivations for participating in classroom research. As the interview findings suggest, teachers find it hard to motivate and engage their students especially during remote teaching. Remote classroom research, if it adequately addresses participants' motivation, can be a powerful motivating experience for them. Exploring participants' motivation will help researchers find ways to address these motivations. For example, when students are curious about what it is like to be a researcher, researchers can consider setting aside time for students to ask questions about the researchers' background and future career goals.

Study Logistics and Context Alignment. Researchers need to ensure that the technology used can be navigated intuitively with no technical bugs. They also need to be prepared for unexpected events during remote studies [5] such as sudden internet outages and technical difficulties (e.g., students cannot log into the system in an asynchronous setting). Also, researchers are expected to make a study plan that allows for flexibility regarding multiple aspects of the study (e.g., the difficulty of the problems assigned to students) to accommodate any needs or preferences that the teacher or students have. Understanding such needs and preferences will help make study participation easier, more streamlined, and more aligned with classroom practices and curriculum requirements.

Equity in Participation. We suggest that researchers consider equity in student participation as a core component of the studies they design for remote classroom research. As the findings of the present study as well as other recent work $[11,12,18]$ suggest, the shift to remote learning due to COVID-19 has exacerbated existing inequalities regarding the support and resources students have access to, including access to learning technologies, increased family responsibilities, and lack of support from parents and

peers. These gaps among students might affect study participation, engagement, and learning in remote classroom research [17]. Exploring what kinds of inequalities researchers need to expect will help them make the study more accessible. For instance, by understanding individual differences in device access among students in advance, researchers can adjust their study design, develop an alternative study participation plan for students with limited access to internet and devices, and design ways for assessing variability in students' learning environment to appropriately consider any potential influence such differences may have on study results.

\subsection{How would the Teaching Mode Affect Remote Classroom Research?}

The proposed framework offers guidance for how researchers could prepare for remote classroom data collection, but the teaching mode and that of researcher participation 
(Figure 1) would also significantly influence the planning. We propose that all five dimensions in the framework need to be considered in accordance with the modes of teaching and researcher participation (Figure 2). Based on our interviews and prior work $[7,13,14,19]$, we think that, as the mode of teaching and researcher participation become less connected (i.e., from physical to remote, from synchronous to asynchronous interaction), the importance of considering the dimensions will increase. When communication channels are limited, it becomes more challenging to intervene and support students (e.g., hard to observe what students are doing and offer help in a timely manner) $[7,10,19]$. Therefore, in a less-connected classroom research environment, it would be more important to carefully consider study facilitation strategies, develop ways to motivate participants, give sufficient access to resources for students' individual learning, streamline study procedure and consider the alignment between the study and classroom practices, and offer an opportunity to participate in the study for students who have limited internet or device access. On the other hand, when the study is conducted in a more connected setting (e.g., Figure 2, B), it would be easier to have direct, synchronous communications and provide support, it would not be as hard to motivate participants, and there would be strong need for resource access for classroom use (by teachers, rather than access for students' individual learning). Researchers could also consider more complicated study designs and could expect narrower gaps among students regarding their learning environment since they are all joining from their classroom synchronously, instead of their own home environment [7].

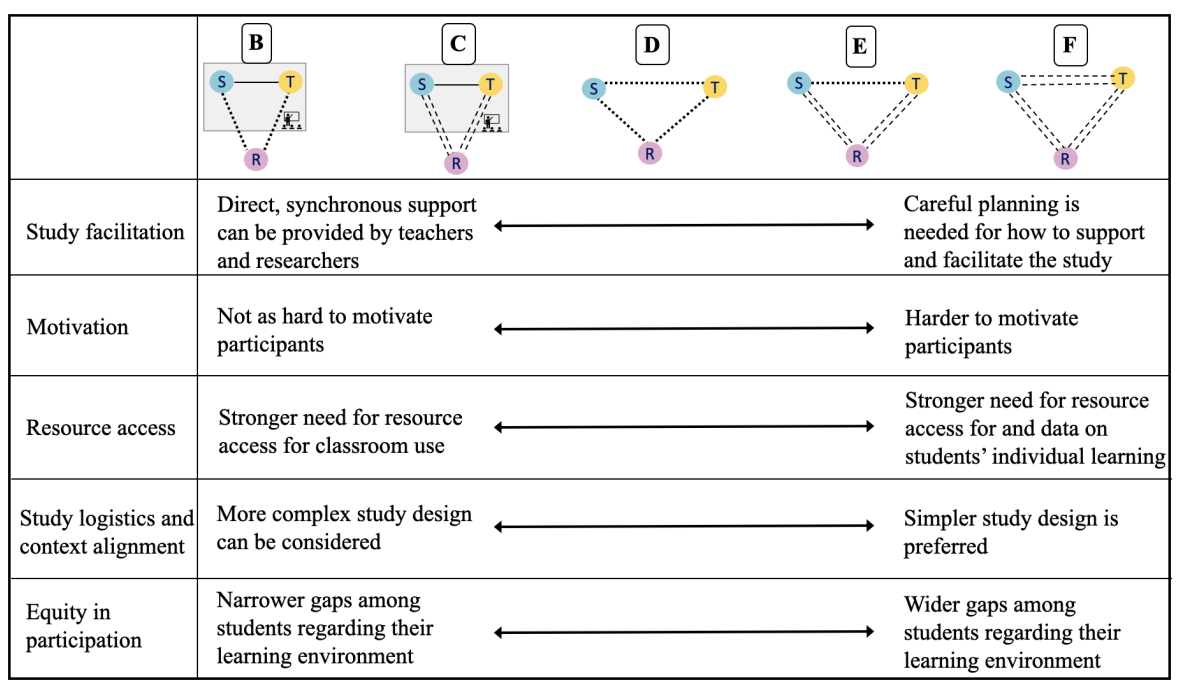

Fig. 2. A model of how the teaching mode can affect remote classroom research. As the teaching mode becomes less connected (from B to F), more careful planning and coordination are needed between researchers and the classroom teacher (and students) to ensure that students can participate in and complete the study and benefit from the study participation experience.

Finally, it is important to note that the framework and many of our findings could be generalized to in-person in-vivo classroom research where it is equally important to 
consider practitioners' viewpoints. In fact, practical considerations in classroom research, especially in the in-vivo research context, are underexplored [20]. Also, even after some challenges might be mitigated after the chaotic time in 2020-21, many of the proposed considerations would still be useful as remote classroom research may continue to exist as a means of classroom research. Therefore, although the proposed model is designed for remote classroom research based on teacher interviews during the COVID-19 pandemic, we think that there are elements that will be useful for remote and in-person classroom studies conducted when schools are back to normal.

\section{Conclusion}

The transition to a new learning environment has forced educational technology researchers to make a transition from in-person to remote data collection, which created new challenges. Our interviews with teachers illustrated that teachers perceive both benefits and challenges in participating in remote classroom studies. Our framework for conducting remote classroom research provides guidance for how educational technology researchers can plan and facilitate remote classroom research, which would continue to exist. We acknowledge, however, that our findings with seven mathematics teachers, who already had an interest in participating in research, may not cover a full range of potential benefits and challenges that teachers and students might experience, and their perceived benefits and challenges might not reflect the actual benefits and challenges they would receive. Also, the small sample is not likely to be representative of school teachers as a whole; it is, however, representative of teachers interested in using educational technology. Our work contributes to the educational technology research community by offering a practical guide that can be used widely by researchers.

\section{Acknowledgements}

This research was supported by NSF Award \#1760922. We thank all the participating teachers. This file is not a final authenticated publication. Once the link is made available, this file will be replaced with the version with the link to the published version.

\section{References}

1. Koedinger, K. R., Aleven, V., Roll, I., Baker, R.: In vivo experiments on whether supporting metacognition in intelligent tutoring systems yields robust learning. Handbook of metacognition in education, pp. 897-964 (2009).

2. Nagashima, T., Bartel, A. N., Yadav, G., Tseng, S., Vest, N. A., Silla, E. M., Alibali, M. W., Aleven, V.: Using anticipatory diagrammatic self-explanation to support learning and performance in early algebra. In E. de Vries, J. Ahn, \& Y. Hod (Eds.), 15th International Conference of the Learning Sciences (pp. 474-481). International Society of the Learning Sciences (2021).

3. Amiel, T., Reeves, T. C.: Design-based research and educational technology: Rethinking technology and the research agenda. Journal of Educational Technology and Society, 11(4), 29-40 (2008). 
4. Coburn, C. E., Penuel, W. R.: Research-practice partnerships in education: Outcomes, dynamics, and open questions. Educational Researcher, 45(1), 48-54 (2016).

5. Lee, K. J., Roldan, W., Zhu, T. Q., Saluja, H. K., Na, S., Chin, B., Zeng, Y., Lee, J. H., Yip, J.: The show must go on. A conceptual model of conducting synchronous participatory design with children online. In Proceedings of the ACM Conference on Human Factors in Computing Systems. Yokohama, Japan (2021).

6. Ratcliffe, J., Soave, F., Bryan-Kinns, N., Tokarchuk, L., Farkhatdinov, I.: Extended reality (XR) remote research: a survey of drawbacks and opportunities. In Proceedings of the ACM Conference on Human Factors in Computing Systems. Yokohama, Japan (2021).

7. Rhodes, M., Rizzo, M. T., Foster-Hanson, E., Moty, K., Leshin, R. A., Wang, M., Benitez, J., Ocampo, J. D.: Advancing developmental science via unmoderated remote research with children, Journal of Cognition and Development, 21(4), 477-493 (2020).

8. Middleton, K. V.: The longer-term Impact of COVID-19 on K-12 student learning and assessment. Educational Measurement: Issues and Practice, 39(3), 41-44 (2020).

9. Nussenbaum, K., Scheuplein, M., Phaneuf, C. V., Evans, M. D., Hartley, C. A.: Moving developmental research online: comparing in-lab and web-based studies of model-based reinforcement learning. Collabra: Psychology, 6(1) (2020).

10. Castelli, F. R., Sarvary, M. A.: Why students do not turn on their video cameras during online classes and an equitable and inclusive plan to encourage them to do so. Ecology and Evolution (2021).

11. Patrick, S. W., Henkhaus, L. E., Zickafoose, J. S., Lovell, K., Halvorson, A., Loch, S., Letterie, M., Davis, M. M.: Well-being of parents and children during the COVID-19 pandemic: a national survey. Pediatrics, 146(4) (2020).

12. Reich, J., Buttimer, C. J., Coleman, D., Colwell, R. D., Faruqi, F., Larke, L. R.: What's lost, what's left, what's next: Lessons learned from the lived experiences of teachers during the 2020 novel coronavirus pandemic. EdArXiv (2020).

13. Smith, C. J.: Getting the most out of remote research and testing. Interactions, 24(2), 82-84 (2017).

14. Doyle, W.: Ecological approaches to classroom management. Handbook of classroom management: Research, practice, and contemporary issues, 97-125 (2006).

15. Lucero, A.: Using affinity diagrams to evaluate interactive prototypes. In IFIP Conference on Human-Computer Interaction, pp. 231-248. Springer, Cham (2015).

16. Laursen, S., Liston, C., Thiry, H., Graf, J.: What good is a scientist in the classroom? Participant outcomes and program design features for a short-duration science outreach intervention in K-12 classrooms. CBE-Life Sciences Education, 6(1), 49-64 (2007).

17. Stelitano, L., Doan, S., Woo, A., Diliberti, M. K., Kaufman, J. H., Henry, D.: The digital divide and COVID-19: Teachers' perceptions of inequalities in students' internet access and participation in remote learning. RAND Research Report (2020).

18. Panaoura, R.: Parental involvement in children's mathematics learning before and during the period of the COVID-19. Social Education Research, 65-74 (2021).

19. Gills, A., Krull, L.: COVID-19 remote learning transition in spring 2020: Class structures, student perceptions, and inequality in college courses. Teaching Sociology, 48(4). 283-299 (2020).

20. Farell, C. C., Davidson, K. L., Repko-Erwin, M., Penuel, W. R., Quantz, M., Wong, H., Riedy, R., Brink, Z.: A descriptive study of the IES Researcher-Practitioner Partnerships in Education Research Program: Final report. National Center for Research in Policy and Practice (2018). 